\title{
Effects of Rapid Maxillary Expansion and Facemask Therapy on the Soft Tissue Profiles of Class III Patients at Different Growth Stages
}

\author{
Fatma Selen Ozzeybek Can ${ }^{1}$ Hakan Turkkahraman ${ }^{1,2, \odot}$ \\ ${ }^{1}$ Department of Orthodontics, School of Dentistry, University of \\ Suleyman Demirel, Isparta, Turkey \\ ${ }^{2}$ Department of Orthodontics and Oral Facial Genetics, School of \\ Dentistry, Indiana University, Indianapolis \\ Address for correspondence Hakan Turkkahraman, DDS, PhD, IU \\ School of Dentistry, 1121 W Michigan St., DS249, Indianapolis, IN \\ 46202, (e-mail: haturk@iu.edu).
}

Eur J Dent 2019;13:143-149

\begin{abstract}
Objectives The aim of this study was to evaluate the effects of rapid maxillary expansion (RME) and facemask therapy on the soft tissue profiles of class III patients at different growth stages.

Materials and Methods Forty-five subjects ( 23 females and 22 males) were divided into prepubertal, pubertal, and postpubertal groups. Bonded type RME appliances and Petit-type facemasks were fitted to each patient, and intraoral elastics were applied from the hooks of the RME appliance to the facemask.

Statistical Analysis All measurements were statistically analyzed with SPSS version 18.0 (SPSS Inc., Chicago, IL, United States) for Windows. Repeated-measures of ANOVA and posthoc Tukey tests were used to compare the groups.

Results The soft tissue nasion, pronasale, subnasale, soft tissue A point, and labrale superior landmarks were all displaced forward and downward, and the most dramatic changes were recorded in the pubertal group. The labrale inferior, soft tissue B point,

Keywords

- facemask

- esthetics

- class III treatment

- soft tissue

- rapid maxillary

expansion soft tissue pogonion, and soft tissue menton landmarks moved backward and downward in all groups, and the greatest displacements were observed in the pubertal group.

Conclusions The soft tissue profiles improved significantly and became more convex in all treatment groups. Although, the most favorable facial changes were observed in the pubertal growth stage, the treatments applied in the postpubertal stage also elicited significant changes and should thus be considered viable treatment options.
\end{abstract}

\section{Introduction}

At the beginning of the 20th century, the primary goal of the orthodontic treatment was to achieve normal occlusion. Therefore, orthodontists focused on the ideal positions and relations of the teeth and their basal bones. However, the soft tissue is the primary determinant of the facial appearances of the patients. After the paradigm shift that occurred in the second half of the 20th century, orthodontists began to place more emphasis on the soft tissue outcomes of their treatments. Today, the patients' and parents' esthetic expectations are more important than ever, and orthodontists should plan their orthodontic treatments to achieve a balanced and esthetic soft tissue profile, a beautiful smile, ideal and stable occlusion, and a healthy temporomandibular joint (TMJ).

The prevalence of class III malocclusion in orthodontically referred populations has been reported to be $12 \%{ }^{1}$ Such malocclusion is characterized by a prognathic/protrusive mandible, rethognathic/retrusive maxilla, protrusive maxillary incisors, retrusive mandibular incisors, a concave soft tissue 
profile, and an anterior cross-bite., ${ }^{2,3}$ The early treatment of class III malocclusion includes the inhibition/modification of mandibular growth with chin-cap ${ }^{4}$ and the stimulation/ modification of maxillary growth with facemask appliances. ${ }^{5}$ Rapid maxillary expansion (RME) is commonly associated with facemask therapy because the maxilla is often transversally underdeveloped and requires expansion. ${ }^{6}$

The early treatment of class III malocclusion has been widely advocated to facilitate maximal growth and development, to create a more normal environment for the growth of the maxilla and the mandible, and to improve facial esthetics for more normal psychosocial development., Early treatment has been reported to enhance the rate of skeletal correction. ${ }^{5,8,9}$ With increasing age, dental correction overwhelms skeletal correction. However, orthodontists are not always able to initiate the class III treatment in the early stage of growth. Treatment becomes more challenging with increasing age and the results and stability of treatments conducted in the pubertal and postpubertal growth stages are questionable.

In the literature, the effects of RME and facemask therapy in the treatment of class III malocclusion have been well documented and investigated. ${ }^{10-14}$ However, some of these studies have mainly focused on hard tissue changes rather than soft tissue changes, ${ }^{13,14}$ and the effects of treatment timing have been considered in only a few studies. ${ }^{7,9,13,15,16}$ To our knowledge, there are no studies that have solely and exclusively evaluated the effects of RME and facemask therapy on the soft tissue profiles of class III patients at different growth stages.

Therefore, the aim of this study was to evaluate the effects of RME and facemask therapy on the soft tissue profiles of class III patients in different growth stages. The results of this study will aid the identification of the optimal treatment timings for the correction of class III anomalies and the accompanying concave soft tissue profiles.

Our null hypothesis was that there would be no difference between the effects of RME and facemask therapy on the soft tissue profiles of class III patients in different growth stages.

\section{Materials and Methods}

This study was approved by the Ethics Committee of the Suleyman Demirel University Faculty of Medicine. Informed consent was obtained from all individual participants included in the study.
Forty-five subjects (23 females and 22 males) who met the following criteria were included in the study:

- Angle class III molar relationship with an anterior cross-bite.

- A concave soft tissue profile.

- Negative ANB and Witt's values.

- In the prepubertal, pubertal, and postpubertal skeletal maturation stage.

- No craniofacial anomalies or systemic diseases.

- No previous orthodontic treatments.

Greulich and Pyle's radiographic atlas ${ }^{17}$ was used for the assessment of the skeletal development of the hand and wrist. The subjects were divided into prepubertal, pubertal, and postpubertal groups according to their skeletal growth period. The prepubertal group consisted of 22 patients in the $\mathrm{PP} 2=$ and MP3= growth stages. The pubertal group consisted of 12 patients in the $S$ and MP3cap growth stages. The post-pubertal group consisted of 11 patients in the DP3u, PP3u, and MP3u growth stages.

The mean ages and treatment periods of the groups are illustrated in - Table $\mathbf{1}$. This study was performed on 90 lateral cephalometric films and hand-wrist radiographs that were acquired before (T1) and at the end of the treatment period (T2).

\section{Appliance Design}

Bonded type RME appliances with 9.0-mm Hyrax screws (Scheu-Dental, Iserlohn, Germany) were fabricated for each patient. The parents were instructed and advised to activate the screws twice daily. One week later, the sutural opening was checked with occlusal radiograph. The screws were activated once daily for the following 10 days and once every 2 days for the subsequent 15 days. After 1 month, the screw was fixed, and the expansion protocol was terminated.

Petit-type facemasks (Ortho Organizer, CA, United States) were fitted to each patient and 5/16 inches, $14 \mathrm{oz}$ intraoral elastics were applied from the hooks of the RME appliance to the facemask. The force vector of the elastics was adjusted to achieve a 20 to 30 degrees angle with the occlusal plane. The applied forces were 300 to 400 grams per side. The patients were advised to change their elastics every day and to wear the appliances for at least 16 to 18 hours per day. Treatment continued until 2-mm positive overjet was obtained. The mean treatment periods were $7.13 \pm 1.32$ months in the prepubertal group, $9.17 \pm 2.97$ months in the pubertal

Table 1 Descriptive statistics according to the chronologic age (in years) and treatment period (in months) of the groups

\begin{tabular}{|l|l|l|l|l|l|l|l|l|l|}
\hline & \multicolumn{4}{|c}{ Chronologic age } & \multicolumn{5}{c|}{ Treatment period } \\
\hline Groups & Mean & SD & Min & Max & Mean & SD & Min & Max \\
\hline Prepubertal & 9.47 & 1.24 & 7.18 & 12.67 & 7.13 & 1.32 & 5.60 & 10.60 \\
\hline Pubertal & 11.80 & 1.44 & 9.00 & 14.04 & 9.17 & 2.97 & 6.10 & 14.93 \\
\hline Postpubertal & 13.35 & 1.81 & 11.13 & 16.76 & 7.69 & 1.08 & 6.30 & 9.57 \\
\hline
\end{tabular}

Abbreviations: SD, standard deviation. 
group, and $7.69 \pm 1.08$ months in the postpubertal group (-Table 1).

\section{Cephalometric Evaluation}

Ten soft tissue landmarks were identified on each cephalogram. The total structural superimposition methods of Björk and Skieller ${ }^{18}$ were used to assess the changes in the positions of the landmarks during the study period. The sella-nasion line was used as a horizontal reference line (X) in the total structural superimposition. A perpendicular line passing through the sella was drawn to the horizontal axis and used as a vertical reference line $(\mathrm{Y})$. The distances of 10 landmarks on the $\mathrm{X}$ and $\mathrm{Y}$ coordinate axes were measured to determine the exact positional changes of the anatomic landmarks (-Table 2). All cephalometric tracings and measurements were performed by the same researcher.

The measurements were performed using a NemoCeph NX Imaging System (Nemotech; Madrid, Spain).

\section{Statistical Analysis}

All measurements were statistically analyzed with SPSS version 18.0 (SPSS Inc., Chicago, IL, United States) for Windows. The Kolmogorov-Smirnov test was used to test the normalities of the data distributions. Repeated-measures ANOVAs and posthoc Tukey tests were used to compare the groups, and to investigate the interactions between the group (prepubertal, pubertal, and postpubertal) and time factors (T1 and $\mathrm{T} 2$ ).

\section{Results}

To calculate the method error of the study, 20 of the 90 lateral cephalometric films were randomly selected, and both the tracings and measurements were repeated within 1 month. The repeatability coefficients were calculated using the analysis of variance. The coefficients were found to be very close to 1.00 .

The ANOVA results regarding the measurements are displayed in - Table 3. Statistically significant group $X$ time interactions were observed in the Pnx, Snx, Sny, A'x, A'y, Lsx, Lsy, Sty, Liy, B'y, and Me'y measurements $(p<0.05)$. The Pnx, Snx, A'x and Lsx measurements were significantly increased in all groups, which indicated the forward movements of the related landmarks $(p<0.05)$. The Sny, A'y, Lsy, Sty, Liy, B'y, and Me'y measures were significantly increased in all groups, which indicated the downward movements of the related landmarks $(p<0.05)$.

The displacements of the soft tissue landmarks resulting from the treatments are displayed in $\boldsymbol{- F i g s .} 1$ to $\mathbf{4}$. The soft tissue nasion, pronasale, subnasale, soft tissue A point, and labrale superior landmarks were all displaced forward and downward, and the most dramatic changes were observed in the pubertal group (-Figs. 1 and 2 ). The stomion moved slightly forward and mostly downward in the prepubertal group, whereas this movement was nearly completely downward in the pubertal group and backward and downward in the postpubertal group ( - Fig. 2). The labrale inferior, soft tissue B point, soft tissue pogonion, and soft tissue menton landmarks moved backward and downward in all groups,

Table 2 Description of the measurements

\begin{tabular}{|l|l|}
\hline N'x & Perpendicular distance of the soft tissue nasion to vertical reference plane \\
\hline N'y & Perpendicular distance of the soft tissue nasion to horizontal reference plane \\
\hline Pnx & Perpendicular distance of the pronasale to vertical reference plane \\
\hline Pny & Perpendicular distance of the pronasale to horizontal reference plane \\
\hline Snx & Perpendicular distance of the subnasale to vertical reference plane \\
\hline Sny & Perpendicular distance of the subnasale to horizontal reference plane \\
\hline A'x & Perpendicular distance of the soft tissue A point to vertical reference plane \\
\hline A'y & Perpendicular distance of the soft tissue A point to horizontal reference plane \\
\hline Lsx & Perpendicular distance of the labrale superior to vertical reference plane \\
\hline Lsy & Perpendicular distance of the labrale superior to horizontal reference plane \\
\hline Stx & Perpendicular distance of the stomion to vertical reference plane \\
\hline Sty & Perpendicular distance of the stomion to horizontal reference plane \\
\hline Lix & Perpendicular distance of the labrale inferior to vertical reference plane \\
\hline Liy & Perpendicular distance of the labrale inferior to horizontal reference plane \\
\hline B'x: & Perpendicular distance of the soft tissue B point to vertical reference plane \\
\hline B'y & Perpendicular distance of the soft tissue B point to horizontal reference plane \\
\hline Pog'x & Perpendicular distance of the soft tissue pogonion to vertical reference plane \\
\hline Pog'y & Perpendicular distance of the soft tissue pogonion to horizontal reference plane \\
\hline Me'x & Perpendicular distance of the soft tissue menthon to vertical reference plane \\
\hline Me'y & Perpendicular distance of the soft tissue menthon to horizontal reference plane \\
\hline
\end{tabular}


Table 3 ANOVA results for the measurements

\begin{tabular}{|c|c|c|c|c|c|c|}
\hline & \multicolumn{2}{|c|}{ Prepubertal } & \multicolumn{2}{|c|}{ Pubertal } & \multicolumn{2}{|c|}{ Postpubertal } \\
\hline & $\mathrm{T} 1$ & $\mathrm{~T} 2$ & $\mathrm{~T} 1$ & $\mathrm{~T} 2$ & $\mathrm{~T} 1$ & $\mathrm{~T} 2$ \\
\hline & Mean \pm SD & Mean \pm SD & Mean \pm SD & Mean \pm SD & Mean \pm SD & Mean \pm SD \\
\hline N'x & $72.40 \pm 0.80$ & $72.89 \pm 0.76$ & $75.42 \pm 1.08$ & $76.16 \pm 1.03$ & $76.96 \pm 1.13$ & $77.45 \pm 1.08$ \\
\hline N'y & $4.63 \pm 0.52$ & $5.69 \pm 0.53$ & $4.31 \pm 0.71$ & $5.85 \pm 0.71$ & $3.51 \pm 0.74$ & $4.68 \pm 0.74$ \\
\hline $\operatorname{Pnx}$ & $85.11 \pm 1.15 \mathrm{Bb}$ & $87.73 \pm 1.25 \mathrm{Ba}$ & $90.97 \pm 1.56 \mathrm{Ab}$ & $94.54 \pm 1.69 \mathrm{Aa}$ & $94.93 \pm 1.63 \mathrm{Ab}$ & $96.68 \pm 1.76 \mathrm{Aa}$ \\
\hline Pny & $48.33 \pm 0.96$ & $48.92 \pm 1.06$ & $50.12 \pm 1.30$ & $51.89 \pm 1.43$ & $52.50 \pm 1.35$ & $53.07 \pm 1.50$ \\
\hline $\operatorname{Snx}$ & $70.37 \pm 1.15 \mathrm{Bb}$ & $72.80 \pm 1.22 \mathrm{Aa}$ & $74.98 \pm 1.56 \mathrm{ABb}$ & $78.17 \pm 1.65 \mathrm{Aa}$ & $78.64 \pm 1.63 \mathrm{Ab}$ & $80.23 \pm 1.72 \mathrm{Aa}$ \\
\hline Sny & $57.15 \pm 0.83 \mathrm{Bb}$ & $58.43 \pm 0.88 \mathrm{Aa}$ & $59.77 \pm 1.12 \mathrm{ABb}$ & $61.97 \pm 1.19 \mathrm{Aa}$ & $61.38 \pm 1.17 \mathrm{Ab}$ & $62.00 \pm 1.24 \mathrm{Aa}$ \\
\hline$A^{\prime} x$ & $68.30 \pm 1.24 \mathrm{Bb}$ & $71.54 \pm 1.34 \mathrm{Ba}$ & $73.15 \pm 1.68 \mathrm{ABb}$ & $76.54 \pm 1.81 \mathrm{ABa}$ & $76.39 \pm 1.76 \mathrm{Ab}$ & $77.97 \pm 1.89$ Aa \\
\hline$A^{\prime} y$ & $64.09 \pm 0.81 \mathrm{Bb}$ & $65.76 \pm 0.92 \mathrm{Aa}$ & $66.48 \pm 1.09 \mathrm{ABb}$ & $69.23 \pm 1.25 \mathrm{Aa}$ & $67.83 \pm 1.14 \mathrm{Ab}$ & $68.97 \pm 1.30 \mathrm{Aa}$ \\
\hline Lsx & $69.75 \pm 1.40 \mathrm{Bb}$ & $73.02 \pm 1.50 \mathrm{Ba}$ & $75.16 \pm 1.89 \mathrm{ABb}$ & $78.75 \pm 2.03 \mathrm{ABa}$ & $78.52 \pm 1.98$ Aa & $79.73 \pm 2.12 \mathrm{Aa}$ \\
\hline Lsy & $71.67 \pm 0.87 \mathrm{Bb}$ & $73.93 \pm 1.02 \mathrm{Ba}$ & $74.27 \pm 1.18 \mathrm{ABb}$ & $78.45 \pm 1.38 \mathrm{Aa}$ & $75.72 \pm 1.23 \mathrm{Ab}$ & $76.64 \pm 1.44 \mathrm{ABa}$ \\
\hline Stx & $64.84 \pm 1.51$ & $65.45 \pm 1.50$ & $70.42 \pm 2.05$ & $70.45 \pm 2.04$ & $73.52 \pm 2.14$ & $72.26 \pm 2.13$ \\
\hline Sty & $75.72 \pm 0.91 \mathrm{Bb}$ & $78.95 \pm 1.03 \mathrm{Ba}$ & $78.83 \pm 1.23 \mathrm{ABb}$ & $84.36 \pm 1.40 \mathrm{Aa}$ & $80.86 \pm 1.29 \mathrm{Ab}$ & $82.68 \pm 1.46 \mathrm{ABa}$ \\
\hline Lix & $69.50 \pm 1.58$ & $67.94 \pm 1.63$ & $75.50 \pm 2.14$ & $73.02 \pm 2.20$ & $78.22 \pm 2.24$ & $75.43 \pm 2.30$ \\
\hline Liy & $83.23 \pm 1.14 \mathrm{Bb}$ & $86.73 \pm 1.17 \mathrm{Ba}$ & $86.29 \pm 1.55 \mathrm{ABb}$ & $93.14 \pm 1.58 \mathrm{Aa}$ & $89.04 \pm 1.61 \mathrm{Ab}$ & $90.76 \pm 1.65 \mathrm{ABa}$ \\
\hline$B^{\prime} x$ & $61.85 \pm 1.56$ & $58.64 \pm 1.66$ & $67.49 \pm 2.12$ & $62.73 \pm 2.24$ & $69.92 \pm 2.21$ & $66.95 \pm 2.34$ \\
\hline B’y & $92.92 \pm 1.09 \mathrm{Bb}$ & $94.82 \pm 1.26 \mathrm{Ba}$ & $96.95 \pm 1.46 \mathrm{ABb}$ & $101.88 \pm 1.71 \mathrm{Aa}$ & $99.28 \pm 1.54 \mathrm{Aa}$ & $100.03 \pm 1.78 \mathrm{Aa}$ \\
\hline Pog'x & $59.48 \pm 1.75$ & $56.06 \pm 1.89$ & $66.10 \pm 2.37$ & $60.08 \pm 2.56$ & $70.11 \pm 2.48$ & $65.62 \pm 2.68$ \\
\hline Pog'y & $107.50 \pm 1.22$ & $110.06 \pm 1.37$ & $111.46 \pm 1.66$ & $115.39 \pm 1.85$ & $114.26 \pm 1.73$ & $116.94 \pm 1.94$ \\
\hline Me’x & $42.31 \pm 1.99$ & $38.94 \pm 2.14$ & $48.71 \pm 2.69$ & $42.71 \pm 2.90$ & $53.72 \pm 2.81$ & $48.91 \pm 3.03$ \\
\hline Me’y & $117.56 \pm 1.43 \mathrm{Bb}$ & $120.44 \pm 1.65 \mathrm{Ba}$ & $123.36 \pm 1.93 \mathrm{ABb}$ & $128.25 \pm 2.23 \mathrm{Aa}$ & $125.72 \pm 2.02 \mathrm{Ab}$ & $127.89 \pm 2.33 \mathrm{Aa}$ \\
\hline
\end{tabular}

Abbreviation: SD, standard deviation.

Note: Capital letters reveal significant differences between groups, and small letters reveal significant differences between T1 and T2.

and the greatest displacements were observed in the pubertal group ( - Figs. 3 and 4$)$.

\section{Discussion}

The chief concerns of class III patients are their facial appearances. Improvements in appearance positively contribute to patients' appearances, self-concepts and psychosocial well-being during the teenage years.,19 Therefore, this study primarily focused on the soft tissue changes that occurred after RME and facemask treatments.

The nose continues to grow in a downward and forward direction until adulthood. ${ }^{20}$ The nasal tip has been reported to move forward by approximately $1 \mathrm{~mm}$ annually. ${ }^{20,21}$ Nanda et $\mathrm{al}^{21}$ reported a rapid increase in nose height between 7 and 8 years, followed by slower increases between 8 to 11 years and additional accelerations at 11 years and from 14 to 17 years. In our study, the nasal tips moved forward and slightly downward in all treatment groups, and the greatest amount of forward displacement was observed in the pubertal group $(3.57 \mathrm{~mm})$. This forward movement amount was far greater than the expected soft tissue growth and was primarily caused by the forward displacement of the maxilla and anterior nasal spine due to the protraction forces. Our results are consistent with those of previous studies that have reported increased amounts of forward displacement of the nasal tip with protraction forces. ${ }^{22}$ The reduced forward displacements of the pronasale in the postpubertal group might have resulted from decreased skeletal changes during this period and a slowing of the sagittal growth of the nose.

The upper lip reflects changes in the underlying bony structures of the premaxilla and the upper incisors, ${ }^{21}$ and significant forward displacements of the A point and labial tipping of the incisors have been reported to result from

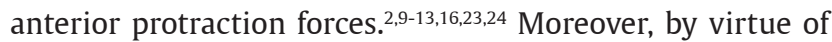
its attachment to the nose, the position of the upper lip is affected by the growth of the nose. ${ }^{20}$ The effect of the treatment was found to be more prominent in the upper lip area, which is consistent with previous studies. ${ }^{10,12,22,24}$ Kapust et al ${ }^{10}$ reported forward movement of the upper lip of $3.25 \mathrm{~mm}$, whereas the lower lip moved backward by only $0.68 \mathrm{~mm}$, which is nearly a five-fold difference. The upper lips moved forward and downward in all groups. The amounts of displacement were similar in the prepubertal and pubertal groups. However, the least forward displacement was observed in the postpubertal group. Consistent with our results, Halicioglu et $\mathrm{a}^{11}$ reported no significant changes in the anteroposterior position of the upper lip after RME and facemask therapy in young adults. This finding might have resulted from decreased maxillary forward movement in 


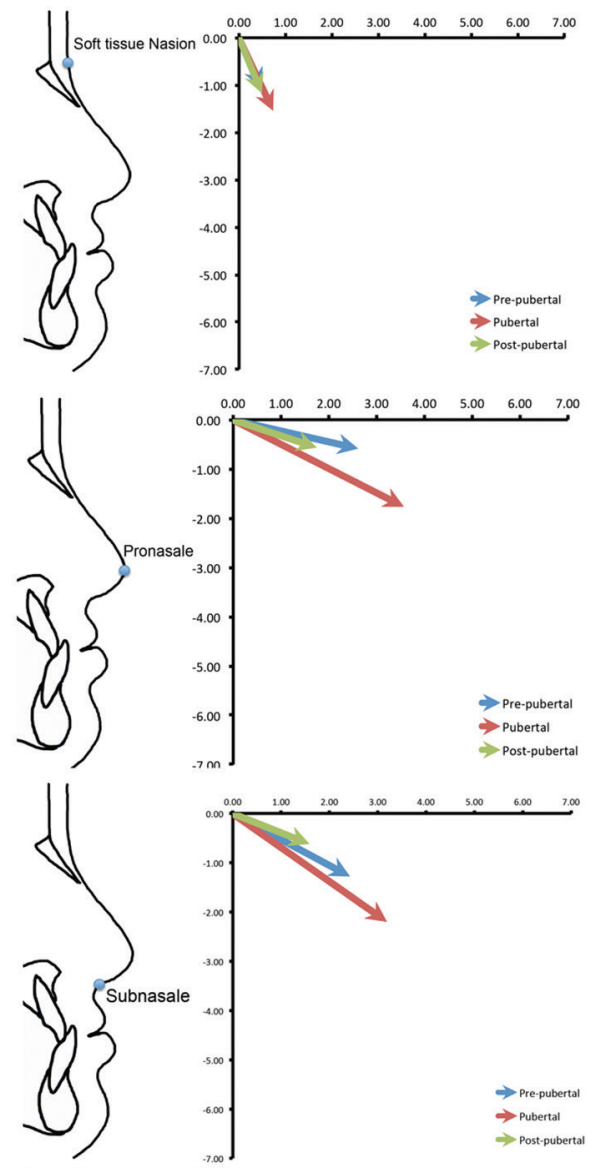

Fig. 1 Displacement of the landmarks: soft tissue nasion, pronasale, and subnasale.

postpubertal patients, which has been reported in several studies. ${ }^{8,10,13,24}$

The position of the lower lip has been reported to be largely dependent on the incisor inclination. ${ }^{21}$ One of the most significant effects of the facemask therapy is the retrusion of the lower incisors due to the pressure exerted with the chincap unit.,3,10-12,24 The retrusion of the lower incisors results in retrusion of the lower lips. Moreover, the lower lip is not only affected by the retrusion of the lower incisors but also by the protrusion of the upper incisors due to the correction of the anterior cross-bite. ${ }^{22}$ In the present study, we observed significant backward and downward lower lip displacements in all groups, and these findings are consistent with previous studies. ${ }^{10,12}$ No difference in backward displacement was observed between the groups. The greatest downward displacement was observed in the pubertal group, whereas the least displacement was observed in the postpubertal group. In contrast with our results, Halicioglu et $\mathrm{al}^{11}$ reported no significant changes in the position of the lower lip in young adults who were treated with facemasks with or without RME. However, the mean age of their sample was at least 1 -year-older than that of our sample, and this difference might have affected the results. Yavuz et al ${ }^{24}$ also reported no significant changes in the positions of the lower lip of adolescents and young adults.

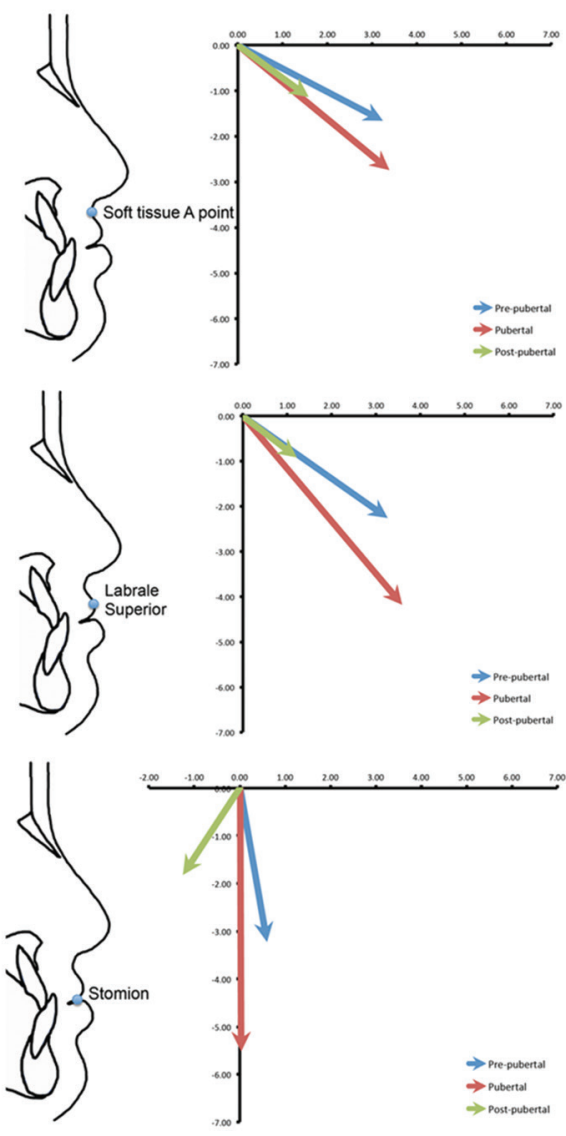

Fig. 2 Displacement of the landmarks: soft tissue A point, labrale superior, and stomion.

The soft tissue chin has been demonstrated to be closely related to the position of the skeletal chin, ${ }^{20}$ which indicates that the extents of increases or decreases in the prominence of the soft tissue chin are closely correlated with the degrees of change in the prominence of the skeletal chin..$^{20}$ Therefore, orthodontists can successfully alter the position of the soft tissue chin by stimulating, inhibiting, or modifying mandibular growth. Nanda et al ${ }^{21}$ reported that the soft tissue thicknesses at the level of the soft tissue pogonion exhibit total increases of $2.7 \mathrm{~mm}$ in males and $2.0 \mathrm{~mm}$ in females during normal growth between the ages of 7 to 18 years. This finding indicates that approximately $2.5 \mathrm{~mm}$ of forward displacement of the soft tissue pogonion occurs during 11 years of growth and development. Particularly in class III patients, greater forward growth of the mandible is expected to result in considerable forward movements of the skeletal and soft tissue chins. However, in our study, the soft tissue pogonion moved backward and downward significantly in all groups. In the pubertal group, the backward displacement was nearly $6.00 \mathrm{~mm}$. The backward and downward displacement of the soft tissue chin might have resulted from the chincap effect of the facemask, which inhibited the forward growth of the mandible and forced the mandible to rotate posteriorly. ${ }^{16,23,24}$ In accordance with our results, the backward displacement of the soft tissue pogonion has been reported in previous studies. ${ }^{3,10,12,22}$ 

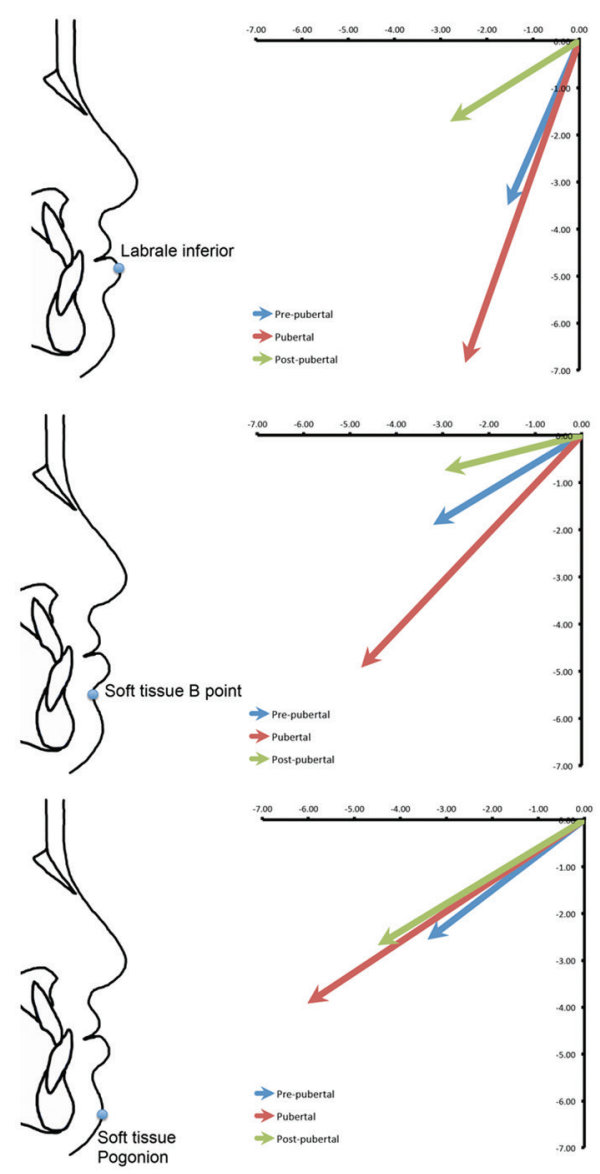

Fig. 3 Displacement of the landmarks: labrale inferior, soft tissue B point, and soft tissue pogonion.

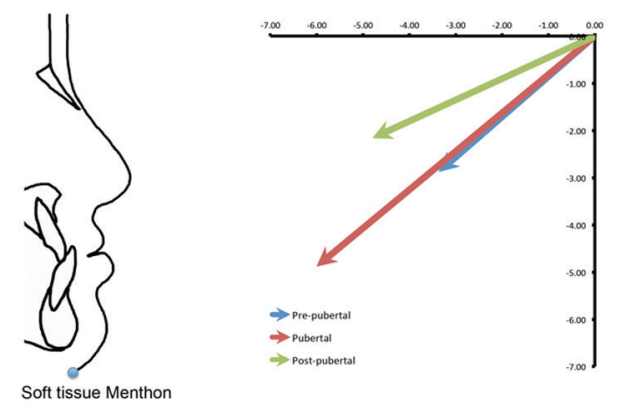

Fig. 4 Displacement of the landmark: soft tissue menton.

Based on the results of this study, our null hypothesis was rejected. There were significant differences between the effects of RME and facemask therapies on the soft tissue profiles of class III patients at different growth stages. These results provide scientific evidence that the treatment of class III anomalies with RME and facemasks during the pubertal growth stage elicit more favorable facial changes than treatment applied in the prepubertal and postpubertal growth stages. Therefore, to achieve favorable facial changes in class III patients, the optimal treatment time seems to be the pubertal period. However, it should not be omitted that RME and facemask therapies are still effective in the postpubertal growth stage, albeit to lesser extents.

\section{Conclusions}

Significant forward movement of the upper lip was observed. However, the least amount of forward displacement was observed in the postpubertal group. The lower lip was displaced backward and downward in all groups. The greatest amount of downward displacement was observed in the pubertal group, whereas the least amount of displacement was observed in the postpubertal group. The soft tissue chin was displaced backward and downward in all groups. The soft tissue profiles significantly improved and became more convex in all treatment groups. Although, the most favorable facial changes were observed in the pubertal growth stage, the treatments applied in the postpubertal stage also elicited significant changes and should thus be considered viable treatment options.

\section{Conflict of Interest \\ None declared.}

\section{Acknowledgment}

We wish to thank Dr. Ozgur Koskan from the Department of Zootechnics of the Faculty of Agriculture of Suleyman Demirel University for his help with the statistical analyses.

\section{References}

1 Sayin MO, Türkkahraman H. Malocclusion and crowding in an orthodontically referred Turkish population. Angle Orthod 2004;74(5):635-639

2 Campbell PM. The dilemma of class III treatment. Early or late? Angle Orthod 1983;53(3):175-191

3 Ngan P, Hägg U, Yiu C, Merwin D, Wei SH. Soft tissue and dentoskeletal profile changes associated with maxillary expansion and protraction headgear treatment. Am J Orthod Dentofacial Orthop 1996;109(1):38-49

4 Sugawara J, Mitani H. Facial growth of skeletal class III malocclusion and the effects, limitations, and long-term dentofacial adaptations to chincap therapy. Semin Orthod 1997;3(4):244-254

5 da Silva Filho OG, Magro AC, Capelozza Filho L. Early treatment of the Class III malocclusion with rapid maxillary expansion and maxillary protraction. Am J Orthod Dentofacial Orthop 1998;113(2):196-203

6 Vaughn GA, Mason B, Moon HB, Turley PK. The effects of maxillary protraction therapy with or without rapid palatal expansion: a prospective, randomized clinical trial. Am J Orthod Dentofacial Orthop 2005;128(3):299-309

7 Saadia M, Torres E. Sagittal changes after maxillary protraction with expansion in class III patients in the primary, mixed, and late mixed dentitions: a longitudinal retrospective study. Am J Orthod Dentofacial Orthop 2000;117(6):669-680

8 Takada K, Petdachai S, Sakuda M. Changes in dentofacial morphology in skeletal class III children treated by a modified maxillary protraction headgear and a chin cup: a longitudinal cephalometric appraisal. Eur J Orthod 1993;15(3):211-221

9 Baccetti T, McGill JS, Franchi L, McNamara JA, Jr. Tollaro I. Skeletal effects of early treatment of class III malocclusion with maxillary expansion and face-mask therapy. Am J Orthod Dentofacial Orthop 1998;113(3):333-343

10 Kapust AJ, Sinclair PM, Turley PK. Cephalometric effects of face mask/expansion therapy in class III children: a comparison of three age groups. Am J Orthod Dentofacial Orthop 1998;113(2):204-212 
11 Halicioglu K, Yavuz I, Ceylan I, Erdem A. Effects of face mask treatment with and without rapid maxillary expansion in young adult subjects. Angle Orthod 2014;84(5):853-861

12 Celikoglu M, Yavuz I, Unal T, Oktay H, Erdem A. Comparison of the soft and hard tissue effects of two different protraction mechanisms in class III patients: a randomized clinical trial. Clin Oral Investig 2015;19(8):2115-2122

13 Cha KS. Skeletal changes of maxillary protraction in patients exhibiting skeletal class III malocclusion: a comparison of three skeletal maturation groups. Angle Orthod 2003;73(1):26-35

14 Masucci C, Franchi L, Defraia E, Mucedero M, Cozza P, Baccetti T. Stability of rapid maxillary expansion and facemask therapy: a long-term controlled study. Am J Orthod Dentofacial Orthop 2011;140(4):493-500

15 Baccetti T, Franchi L, McNamara JA, Jr. Treatment and posttreatment craniofacial changes after rapid maxillary expansion and facemask therapy. Am J Orthod Dentofacial Orthop 2000;118(4):404-413

16 Zhang W, Qu HC, Yu M, Zhang Y. The Effects of maxillary protraction with or without rapid maxillary expansion and age factors in treating class III malocclusion: a meta-analysis. PLoS One 2015;10(6):e0130096
17 Greulich WW, Pyle SI, Radiographic atlas of skeletal development of the hand and wrist. 2nd ed. Stanford, California : Stanford University Press; 1959

18 Björk A, Skieller V. Normal and abnormal growth of the mandible. A synthesis of longitudinal cephalometric implant studies over a period of 25 years. Eur J Orthod 1983;5(1):1-46

19 de Paula Júnior DF, Santos NC, da Silva ET, Nunes MF, Leles CR. Psychosocial impact of dental esthetics on quality of life in adolescents. Angle Orthod 2009;79(6):1188-1193

20 Subtelny JD. The soft tissue profile, growth and treatment changes. Angle Orthod 1961;31(2):105-122

21 Nanda RS, Meng H, Kapila S, Goorhuis J. Growth changes in the soft tissue facial profile. Angle Orthod 1990;60(3):177-190

22 Kiliçoglu H, Kirliç Y. Profile changes in patients with class IIl malocclusions after Delaire mask therapy. Am J Orthod Dentofacial Orthop 1998;113(4):453-462

23 Merwin D, Ngan P, Hagg U, Yiu C, Wei SH. Timing for effective application of anteriorly directed orthopedic force to the maxilla. Am J Orthod Dentofacial Orthop 1997;112(3):292-299

24 Yavuz I, Halicioğlu K, Ceylan I. Face mask therapy effects in two skeletal maturation groups of female subjects with skeletal Class III malocclusions. Angle Orthod 2009;79(5):842-848 